\title{
Une alliance de disciplines sur une question environnementale : la déforestation en forêt des Mikea (Sud-Ouest de Madagascar)
}

\author{
Chantal Blanc-Pamard ${ }^{a}$, Pierre Milleville ${ }^{b}$, Michel Grouzis ${ }^{c}$, Florent Lasry ${ }^{\mathrm{d}}$, Samuel Razanaka ${ }^{\mathrm{e}}$ \\ a Géographe, CNRS, CEAf EHESS, 54 Bd Raspail, 75006 Paris, France \\ b Agronome, IRD, BP 64501, 34394 Montpellier cedex, France \\ c Écologue, IRD, BP 434, 101 Antananarivo, Madagascar \\ d Géomaticien, GIS \& Remote Sensing Training and Research Center, National University of Rwanda, BP 212, Butare, Rwanda \\ e Phytogéographe, CNRE, BP 1739, 101 Antananarivo, Madagascar
}

\begin{abstract}
Que les questions environnementales incitent les disciplines portant sur la nature, la technique et la société à faire alliance, voilà bien un des leitmotive de notre revue. Cet article l'illustre à son tour à partir d'une question, la dynamique de déforestation. L'apport de cette expérience menée pendant six années entre plusieurs disciplines réside en particulier dans l'effort fait par chacune d'elles pour harmoniser leurs échelles d'analyse. Pour cela, les chercheurs ont dû s'accorder autour d'un concept - le territoire - et d'un outil - le Système d'information géographique. Une expérience à verser au dossier, toujours ouvert, de la synergie interdisciplinaire.
\end{abstract}

La Rédaction

\section{Mots-clés :}

déforestation; culture sur abattis-brûlis ; environnement; temps ; territoire; savoirs locaux; transdisciplinarité; Madagascar ; Sud-Ouest

\section{Keywords: deforestation; slash-and-burn agriculture; environment; time; territory; local knowledge; interdisciplinarity; Madagascar}

Résumé - Dans le Sud-Ouest de Madagascar, de grands massifs forestiers sont affectés par un processus de déforestation de grande ampleur, en raison de l'expansion de la culture du maïs sur abattis-brûlis. Dans la forêt des Mikea, site retenu pour son exemplarité par le programme GEREM, le rythme de défrichement a ainsi quadruplé depuis les années 1980. La recherche, conduite de 1996 à 2002, a permis d'évaluer l'ampleur du phénomène, son caractère irréversible, la perte de biodiversité et les changements d'usage des ressources qui en résultaient. Elle a explicité les relations dynamiques entre des types de milieux et des espaces qui changent de nature et d'affectation, ainsi que les stratégies d'acteurs qui leur sont associées. Par-delà les questions, approches et niveaux d'investigation spécifiques de l'écologie, de l'agronomie et de la géographie, cette expérience de recherche montre que les problèmes d'environnement imposent des démarches plus intégrées aux échelles territoriales. Le couplage des questions agraire et environnementale, tout comme celui du temps et de l'espace, appliqué à l'analyse de situations en mutation rapide, ont ainsi créé les conditions d'une réelle alliance entre chercheurs relevant des sciences de la nature, des sciences biotechniques et des sciences sociales.

\begin{abstract}
Ecology, agronomy and geography join forces over an environmental issue: deforestation of the Mikea forest in south-western Madagascar. The GEREM Program (Management of Rural Areas and the Environment in Madagascar) was conducted between 1996 and 2002 in south-western Madagascar. One result of the partnership between the three sciences was the highlighting of deforestation as a major environmental problem. Scientific findings point to the extent of deforestation, its irreversible character, and the resulting loss of biodiversity. Satellite imagery has provided a useful tool for comparing results. The forest of the Mikea, some 100 kilometres from Tulear, was used as an example because of the extent and speed of biodiversity loss. The extent of deforested areas has quadrupled since the late 1980s. Essentially, the cause of deforestation is the slash-and-burn cultivation of corn (maize), locally known as hatsaky. Due to the dynamic interplay between the types of environments and the changing use of land, addressing environmental issues from the angle of each separate discipline is no longer helpful. This study calls for a multidisciplinary and territorialized approach to environmental problems. The GEREM Program seeks to both understand the emerging environmental problem and identify the research issue. By combining agriculture and the environment with time and space scales, the research team has pooled its scientific investigations and produced findings that can be used by all three sciences.
\end{abstract}

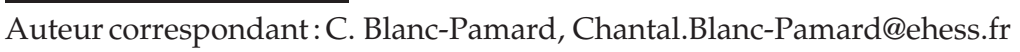


Cet article présente les résultats de recherches interdisciplinaires menées dans le cadre du comité SEAH (Systèmes écologiques et action de l'homme) du programme Environnement, vie et sociétés du CNRS, tout comme six autres contributions précédemment publiées dans la revue :

- P. Allard et al., 2001. Eaux, poissons et pouvoirs. Un siècle de gestion des échanges mer-lagune en Camargue, Natures Sciences Sociétés, 9, 1, 5-18;

- S. Duvail et al., 2001. Gestion de l'eau et interactions société-nature. Le cas du delta du Sénégal en rive mauritanienne, Natures Sciences Sociétés, 9, 2, 5-16;

-C. Albaladejo, 2001. À la recherche d'une agriculture «durable» sur les fronts pionniers : les processus de sédentarisation d'une agriculture familiale en Amazonie et en Argentine, Natures Sciences Sociétés, 9, 2, 29-43;

- G. Fontenelle, 2001. Le programme «Urbamont» (usages et ressources en baie du Mont-Saint-Michel), Natures Sciences Sociétés, 9, 3, 68-70;

- A. Lacroix et A. Mollard, 2002. Bilan scientifique d'une recherche interdisciplinaire entre agronomes, hydrologues et économistes : le point de vue des économistes, Natures Sciences Sociétés, 10, 1, 7-14;

- D. Hervé et al., 2003. Introduction à la modélisation dans une recherche interdisciplinaire : état et gestion des jachères dans les Andes, Natures Sciences Sociétés, 11, 3, 243-254.

Le projet GEREM (Gestion des espaces ruraux et environnement à Madagascar) ${ }^{1}$, engagé en 1996 dans le Sud-Ouest du pays, s'est donné pour objectif de rendre compte des interrelations entre systèmes de production et systèmes écologiques, dans des milieux affectés de mutations agraires rapides, et d'un processus accéléré de déforestation en raison de l'expansion de la culture pionnière du maïs sur abattis-brûlis. Consacrée au couplage d'une question d'environnement (déforestation) et $d$ 'une question agronomique (performances et durabilité des systèmes de culture sur abattis-brûlis), la recherche s'est élargie rapidement aux stratégies d'acteurs. Il s'agissait donc, en mobilisant des chercheurs relevant des sciences de la nature (écologie), des sciences biotechniques (agronomie) et des sciences sociales (géographie), d'explorer les réseaux de détermination entre activités humaines, processus de production et dynamiques du milieu. Il convenait en particulier de ne pas s'en tenir à une évaluation d'impacts, mais d'examiner aussi en retour les réponses des acteurs aux transformations des milieux. Le terme "gestion" adopté dans l'intitulé du programme traduit, d'une part, la reconnaissance du caractère organisé de l'espace rural et de son exploitation par des acteurs, d'autre part, l'objectif, pour l'équipe de recherche, de contribuer à la conception d'alternatives en la matière. Le site de la forêt des Mikea, situé à une centaine de kilomètres de Tuléar, a été retenu pour son exemplarité, compte tenu de l'ampleur et de la rapidité des dynamiques à l'œuvre (Fig. 1).

\section{La déforestation : un problème environnemental}

Avec 13 millions d'hectares, la forêt ne recouvre plus que $20 \%$ environ du territoire de Madagascar. La

\footnotetext{
${ }^{1}$ Conduit en partenariat entre l'IRD (UR « Transitions agraires et dynamiques écologiques») et le CNRE (Centre national de recherches sur l'environnement), avec la collaboration de chercheurs du CNRS et de l'Inra, ce programme a établi des liens avec les Universités d'Antananarivo et de Tuléar.
}

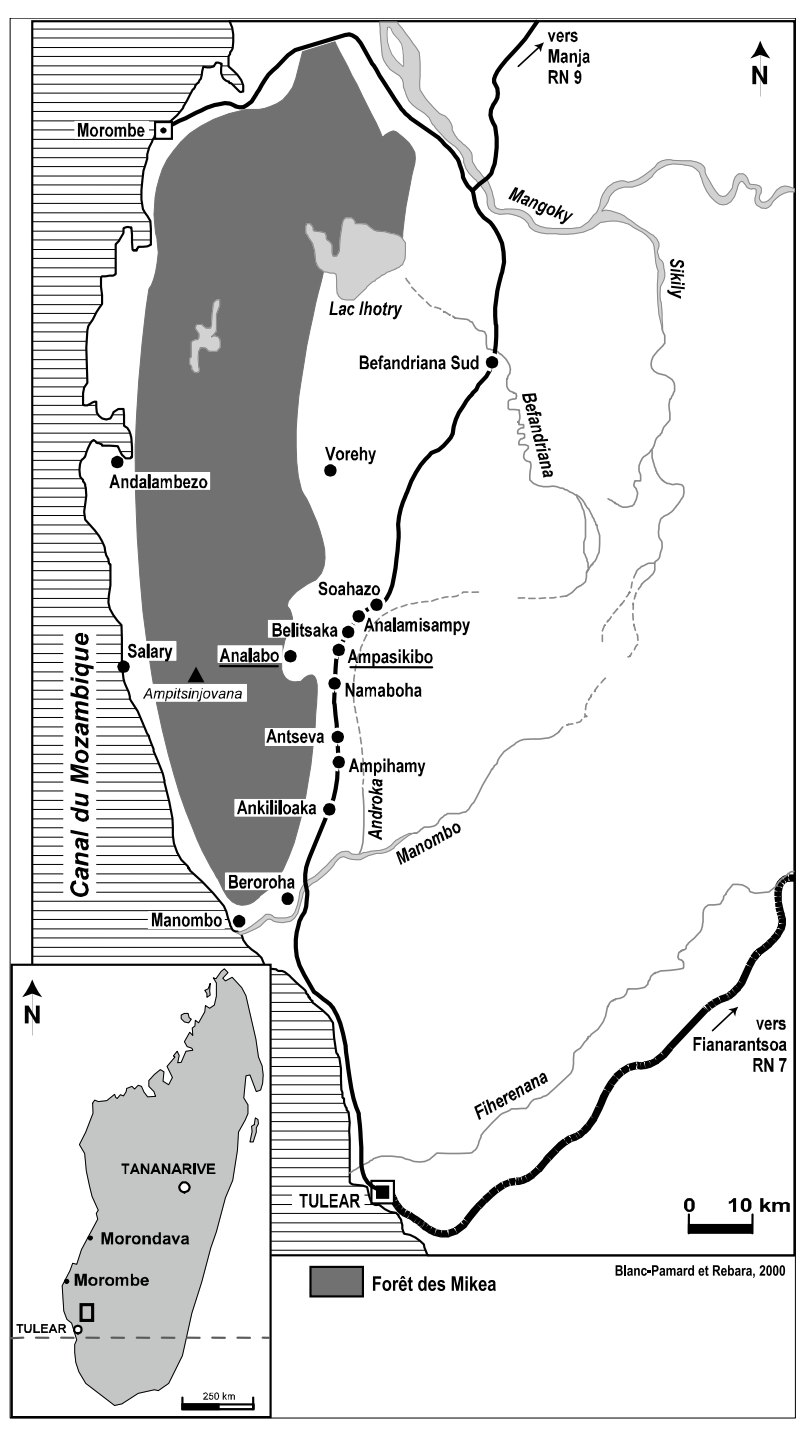

Fig. 1. Carte de localisation.

déforestation atteint des proportions alarmantes. Chaque année, quelque 200000 hectares de forêt disparaîtraient. Ce processus s'est récemment accéléré, tout particulièrement dans le Sud et le Sud-Ouest de l'île. Dans la forêt 


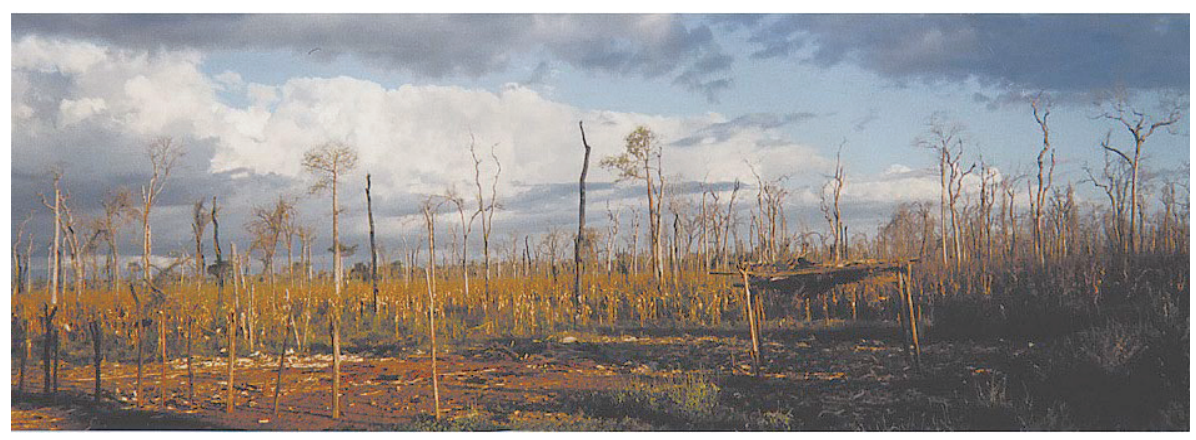

Photo. 1. Culture du maïs après défriche-brûlis (photo C. Blanc-Pamard).

des Mikea, massif forestier de $1500 \mathrm{~km}^{2}$, les surfaces déboisées ont quadruplé depuis la fin des années 1980. La déforestation est à imputer, pour l'essentiel, au développement de la culture du maïs sur abattis-brûlis, appelée localement hatsaky (Photo 1). Cette agriculture pionnière se développe rapidement aux dépens de la forêt, sous l'effet de plusieurs facteurs : une pression démographique accrue par l'arrivée de migrants, une saturation foncière des terres les plus fertiles, le relâchement du contrôle par l'État des défrichements forestiers. Enfin et surtout, culture vivrière à l'origine, le maïs est devenu une culture principalement commerciale, pour répondre aux besoins du marché national et de celui de l'île de la Réunion. La culture du maïs, ainsi stimulée, ne cesse de gagner sur la forêt.

La forêt de l'Ouest, dite forêt des Mikea, est une zone de chasse et de cueillette, perçue comme l'espace sauvage, le monde des esprits. Elle est riche de nombreuses ressources : des tubercules sauvages, du miel, des animaux (hérissons, lémuriens, sangliers...) et différentes essences de bois. C'est le domaine des Mikea, "gens de la forêt ", qui diffèrent des populations voisines, les Masikoro, par leur mode de vie forestier et surtout par leur adaptation à l'absence d'eau (Yount et al., 2001). Ce n'est qu'à partir des années 1920 que des éleveurs masikoro se sont installés dans la région, considérée comme vide d'hommes, où ils ont trouvé des terres de parcours pour leurs troupeaux de zébus et ont créé le village d'Ampasikibo. Des terroirs agricoles se sont développés sur les terres de l'Est en liaison avec les grands booms agricoles qui ont touché la région, d'abord le pois du Cap entre les deux guerres mondiales, puis le coton dès 1980 . De gros villages dont l'importance n'a cessé de croître se sont installés le long de la RN9. Avec le développement de la culture du maïs, dès les années 1970 puis 1980, des campements sont créés en forêt à partir des villages de la RN9. À leur tour, les Masikoro ont accueilli de nombreux migrants, dont les Tandroy originaires du Sud (BlancPamard, 2000).

Cette région se caractérise par un climat tropical semiaride, avec une saison humide unique de 4 à 5 mois (novembre à mars), une pluviométrie annuelle moyenne de l'ordre de $850 \mathrm{~mm}$, une forte variabilité interannuelle des précipitations ${ }^{2}$. Deux grands types de sols sableux d'origine éolienne $\mathrm{s}^{\prime} \mathrm{y}$ distinguent à l'ouest de la RN9 (Leprun, 1998) : d'une part, des sols ferrugineux non lessivés correspondant aux formations dunaires de l'erg ancien (sables roux foncés contenant 10 à $15 \%$ d'argile); d'autre part, les sols intergrades entre les précédents et les sols bruns sub-arides, qui correspondent aux formations dunaires récentes (sables roux clairs avec 5 à $15 \%$ d'argile). Un deuxième ensemble de sols se situe à l'est de la RN9, le long du réseau hydrographique ennoyé du Tsivora. Les matériaux beaucoup plus argileux d'origine colluvio-alluviale portent des sols ferrugineux tropicaux lessivés à taches et concrétions, ou à hydromorphie de profondeur et des sols hydromorphes à pseudo-gley. Dans cet ensemble, on trouve des sols appelés baiboho plus strictement localisés dans ou le long des lits majeurs des axes hydrographiques. Ces terres alluviales constituent les meilleurs sols de la région.

Les formations végétales originelles correspondent à la série des forêts denses sèches à Dalbergia, Commiphora et Hildelgardia définie par Humbert et Cours-Darne (1965). Le peuplement pluristratifié se compose d'une strate arborescente inférieure continue dense d'une dizaine de mètres de haut (Commiphora, Delonix, Givotia...), dominée par une strate arborescente supérieure discontinue d'arbres pouvant atteindre $20 \mathrm{~m}$ (Adansonia za, Euphorbia enterophora...). Le sous-bois arbustif (Grewia, Euphorbia, Pandanus, Baudouina... ) est assez clair, la strate herbacée inexistante (Koechlin et al., 1974; Razanaka, 1995). Cette forêt témoigne de particularités biologiques d'adaptation à l'aridité : réduction du feuillage et caducité, crassulescence, pachycaulie et géophytisme. L'examen des scènes satellites couplé aux relevés de végétation montre que deux types de forêts coexistent (Lasry et al., 2004) : 1'un dominé par des ligneux hauts à couvert dense, qui colonise les sols de l'erg ancien, les plus aptes à la culture ; l'autre caractérisé par des ligneux bas et un recouvrement

\footnotetext{
${ }^{2}$ Les précipitations annuelles enregistrées durant les années d'étude (1996 à 2001) ont varié entre 630 et 1500 mm.
} 


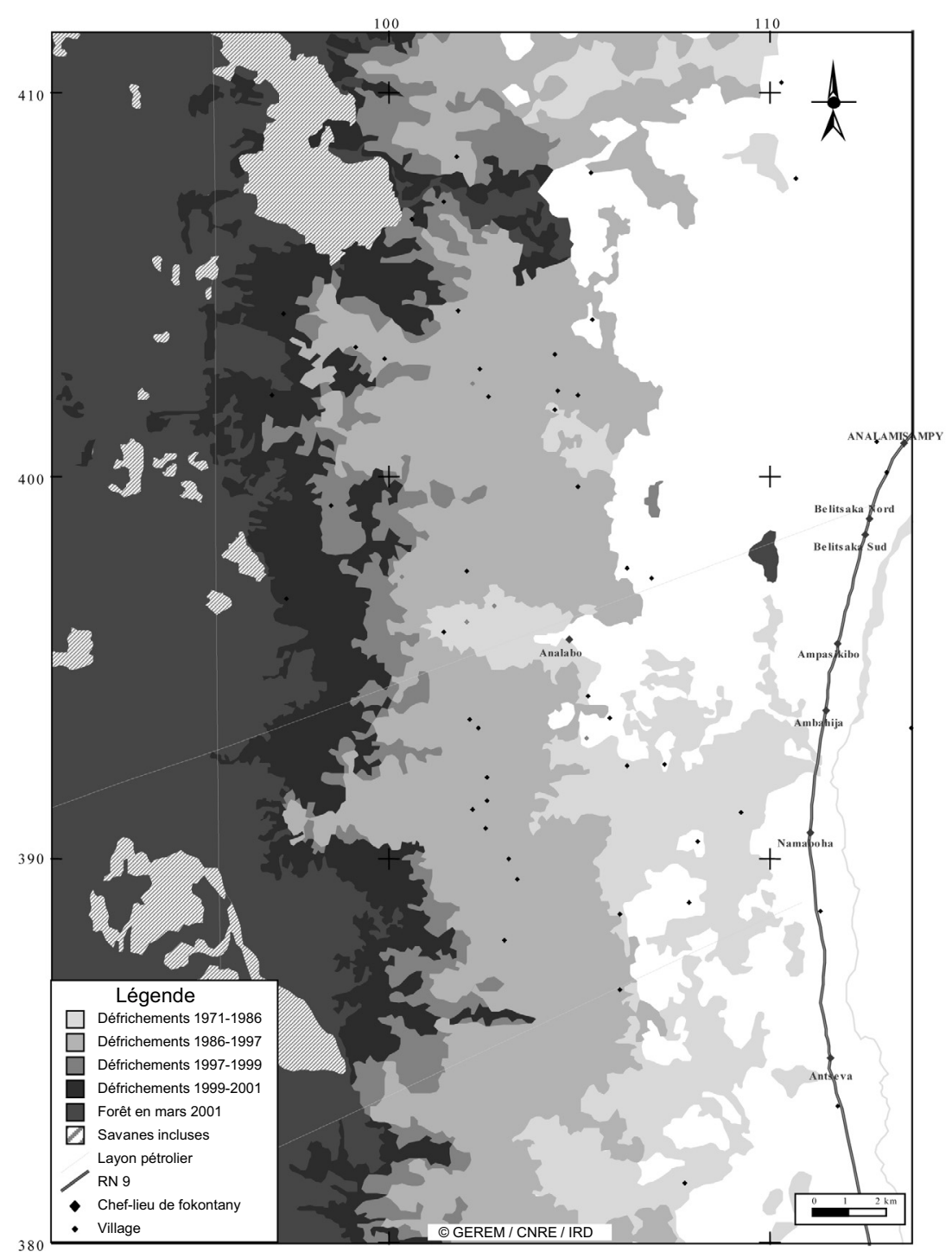

Fig. 2. Évolution de la déforestation entre 1971 et 2001.

plus faible, occupant les sols de l'erg récent. À l'est de la forêt s'étendent des savanes à Heteropogon contortus, avec une strate arborée composée de Tamarindus indica, Poupartia caffra, Gymnosporia linearis...

L'exploitation des photographies aériennes de 1949 et d'images satellites à différentes périodes (1986, 1997, 1999 et 2001), combinée aux travaux de terrain et à une reconnaissance aérienne à basse altitude, a permis de préciser la dynamique et les modalités de la déforestation dans la partie centrale de la forêt des Mikea (Lasry et al., 2004). Les défrichements, engagés véritablement en 1971, ont affecté près de $55 \%$ de la forêt primaire au cours des trente années suivantes (Fig. 2). Mais ce rythme s'est considérablement accéléré au cours du temps : sur l'espace témoin considéré, il est passé de $5,9 \mathrm{~km}^{2} /$ an entre 1971 et 1986 à $19,3 \mathrm{~km}^{2}$ /an entre 1986 et 2001, pour atteindre $34,9 \mathrm{~km}^{2} / \mathrm{an}$ entre 1999 et 2001. La vitesse de déforestation a sextuplé par rapport à la première période, et l'existence même de la forêt des Mikea se trouve donc compromise à brève échéance.

L'analyse des trois dernières images satellites montre que le front de défrichement ne progresse pas de façon linéaire. Des agriculteurs anticipent sur cette avancée, en ouvrant des essarts à l'intérieur de l'espace forestier, afin d'être les premiers à s'attribuer des lots de terre de grande taille qui ne pourront pas ultérieurement leur être contestés; ces îlots se trouveront plus tard inclus dans la zone uniformément cultivée. Par ailleurs, les défrichements apparaissent épouser finement les limites des deux types de forêt identifiés, en évitant soigneusement la forêt basse, dont les sols sont jugés d'une aptitude culturale médiocre. Ces espaces forestiers de "deuxième choix » sont néanmoins défrichés par la suite, à mesure que progresse le front de défrichement et que la forêt haute a disparu. On constate enfin que la plus grande partie des espaces cultivés en 1997 ne l'était plus en 2001, laissant 
place, après quelques années d'exploitation, à des abandons culturaux. Mais sur les friches les plus anciennes, de façon encore limitée, les agriculteurs commencent à ouvrir des parcelles de manioc. En quatre ans, l'emprise des cultures sur ces friches a considérablement augmenté, conséquence de la densification de l'occupation humaine, liée à la création de nouveaux villages à proximité des limites forestières et aux abandons culturaux.

Le coût écologique de la culture sur abattis-brûlis apparaît considérable. La diversité spécifique, évaluée à 146 espèces dans la forêt primaire, se stabilise à 65 espèces environ après 15 années d'abandon cultural (faisant suite à 5 à 8 années de culture). En fait, durant les phases culturale et post-culturale, apparaissent de nombreuses espèces nouvelles (soit une quarantaine entre 2 et 4 ans d'abandon). Après 15 et 30 ans d'abandon, une centaine d'espèces forestières originelles (soit $70 \%$ ) disparaîtraient donc. Celles-ci présentent une importante valeur patrimoniale. En effet, plus de $95 \%$ des taxons sont des espèces ligneuses, plus de $50 \%$ sont des espèces endémiques dont certaines (Euphorbia, orchidées, Aloe) sont inscrites à l'annexe II de la CITES ${ }^{3}$, plus de $15 \%$ des plantes présentent des particularités biologiques d'adaptation à la sécheresse. Par-delà l'érosion de la biodiversité, les travaux d'écologie démontrent que le défrichement de cette forêt, suivi de la pratique du hatsaky, ne permet pas $\mathrm{qu}^{\prime}$ une formation forestière secondaire $\mathrm{s}^{\prime} \mathrm{y}$ installe par la suite.

Par ailleurs, les espèces forestières constituent des ressources exploitées à différentes fins par les populations locales. Dans la forêt des Mikea, une enquête réalisée en 1999 auprès de quelques villageois sur les catégories d'usage des 146 espèces végétales présentes dans deux sites (Raherison, 2000; Rakotojaona, 2000) montre que seules $40 \mathrm{~d}$ 'entre elles sont déclarées sans usage. Les types d'utilisation (hors usage pastoral) des 106 autres espèces se répartissent comme suit, sachant qu'une même espèce peut être utilisée à plusieurs titres : pharmacopée $(29 \%)$, construction $(23 \%)$, outillage (14\%), alimentation (12\%), divination $(10 \%)$, combustible $(3 \%)$, divers $(9 \%)$.

L'exploitation du bois d'œuvre contribue depuis longtemps à une dégradation de l'écosystème forestier, car elle se révèle essentiellement spéculative et minière, ne tenant aucun compte des principes de renouvellement des ressources (Gardette, 1997). La forêt, dans ses sites les plus accessibles, se trouve à présent presque totalement dépouillée des individus d'essences précieuses et semi-précieuses correspondant aux tailles recommandées d'exploitabilité, et les arbres sont coupés de plus en plus jeunes. Dans de telles conditions, il est manifeste que les forêts s'appauvrissent et que le renouvellement des espèces ligneuses exploitées (dont beaucoup sont à

${ }^{3}$ CITES : Convention sur le commerce international de flore et de faune sauvages menacées d'extinction. croissance très lente) s'en trouve fortement compromis. Mais il est vrai que ces prélèvements anarchiques se justifient en partie par la menace que fait peser sur ces sites la progression des défrichements sur les fronts pionniers, dont l'impact écologique est bien plus radical.

Parmi les ressources alimentaires, les tubercules sauvages présentent localement une grande importance (Terrin, 1998; Blanc-Pamard, 2002b ; Aubry et Ramaromisy, 2003). Une dizaine d'entre eux, appartenant notamment au genre Dioscorea (et d'ailleurs présents pour plusieurs d'entre eux dans les hatsaky, les abandons culturaux et les savanes), contribuent pour une part appréciable à l'alimentation et à l'apport en eau. Ces tubercules jouent localement un rôle important comme compléments alimentaires durant la période de soudure alimentaire en saison des pluies. Ils représentent depuis longtemps, avec d'autres ressources végétales spontanées, le miel et les produits de chasse (hérissons, oiseaux), un fondement de l'alimentation des Mikea. Ils sont recherchés également par les populations masikoro et migrantes des villages situés à proximité des limites forestières, tout particulièrement par de petits agriculteurs ne disposant que de surfaces cultivées réduites. Certains de ces tubercules sont par ailleurs proposés sur les marchés locaux, constituant alors des apports de revenus monétaires non négligeables pour les collecteurs.

La disparition accélérée des espaces forestiers se traduit donc par une raréfaction de ressources qui contribuaient, à titre complémentaire ou principal (pour la population mikea), à la satisfaction des besoins vivriers et monétaires.

La dynamique de déforestation en cours aboutit à un déplacement continu vers l'ouest des fronts de défrichement et à une reconversion de la forêt en espaces agricoles et pastoraux. L'accès à la forêt devient de plus en plus difficile pour la plupart des habitants, les ressources qu'ils en tirent s'amenuisent. Ces changements apparaissent acquis et en grande partie irréversibles. Si l'on doit s'interroger sur la poursuite de cette dynamique et sur les moyens de l'enrayer, il convient aussi de se pencher sur la question de la viabilité des systèmes d'exploitation du milieu et des systèmes de production lorsque la composante forestière disparaît (Razanaka, 2004).

\section{Un terrain, des disciplines}

En accord avec la thématique d'ensemble du programme, chaque discipline est conduite à préciser ses propres questions et à recueillir sur le terrain l'information nécessaire, en adoptant des niveaux d'analyse et des méthodes appropriés. Comme dans la plupart des pays du Sud, les données disponibles se révèlent fragmentaires et très insuffisantes, en quantité comme 


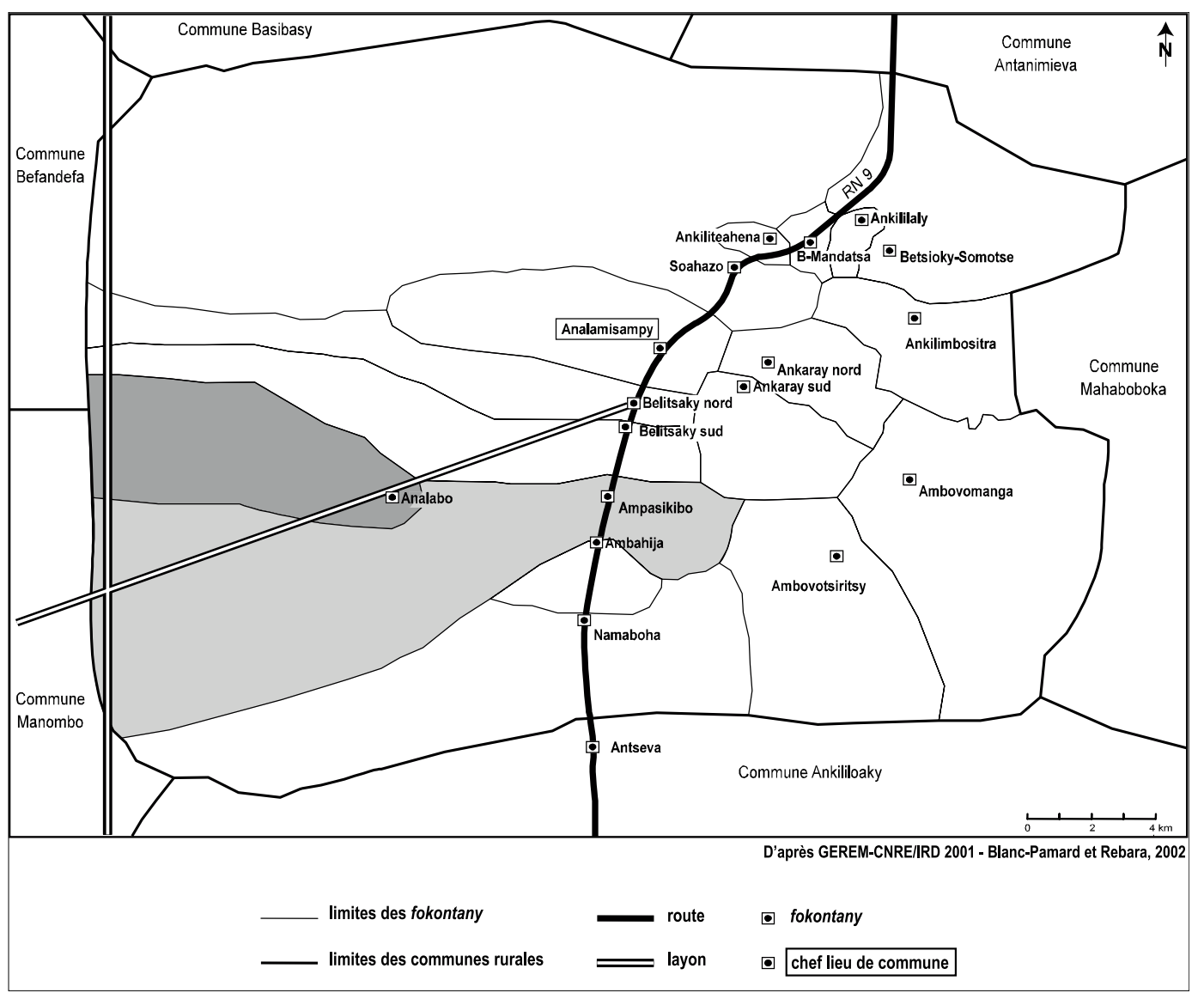

Fig. 3. Carte de la commune d'Analamisampy et des fokontany d'Analabo et d'Ampasikibo.

en qualité, pour alimenter la recherche, qui doit, de ce fait, produire et construire son information. Dans une première phase, l'accent a donc été mis sur la compréhension des processus et l'acquisition des indispensables références. Le choix d'un petit espace rural s'est alors imposé, comme cadre d'analyses particulières et d'exercice de la pluridisciplinarité. Il s'est agi du fokontany ${ }^{4}$ lié au village d'Analabo, riverain lors de sa fondation en 1940 du massif forestier de l'Ouest. Cet espace restreint rassemblait des situations variées (hatsaky et abandons culturaux anciens et récents), permettant d'appréhender dans leur dynamique spatiotemporelle et de relier entre eux des faits relevant de différentes catégories (sociodémographiques, agraires, écologiques). Un tel objectif rendait nécessaire une certaine unité de lieu et le choix de sites pour partie communs. Par la suite, les investigations ont été étendues à de plus amples espaces, en particulier au territoire de la commune rurale $\mathrm{d}^{5}$ Analamisampy (Fig. 3).

\footnotetext{
${ }^{4}$ Fokontany: cellule administrative de base regroupant généralement plusieurs villages et hameaux.

5 À Madagascar, la commune regroupe un ensemble de fokontany et est d'une taille comparable à celle du canton français. La commune d'Analamisampy rassemble ainsi 17 fokontany et 82 villages.
}

Des questions spécifiques relevant des différentes disciplines ou d'interfaces entre ces disciplines ont pu ainsi être traitées :

- Les travaux d'écologie végétale ont permis de caractériser les écosystèmes forestiers, en relation avec le type de sol (Rakotojaona et Grouzis, 2005). Ils ont tout particulièrement porté sur la compréhension des dynamiques temporelles de la végétation et des paramètres édaphiques, en relation avec la pratique de la culture sur abattis-brûlis (Raherison et Grouzis, à paraître). Durant la phase culturale, l'accent a été mis sur la question de l'enherbement, en spécifiant l'évolution au cours du temps des peuplements d'adventices en termes de successions floristiques, de spectre biologique, de recouvrement et de phytomasse (Grouzis et Razanaka, 2001). Le suivi conjoint, par l'écologue et l'agronome, de stations culturales d'ancienneté croissante de mise en culture montre clairement que l'enherbement constitue une contrainte de plus en plus forte pour la conduite de la culture et qu'il exerce un effet dépressif majeur sur le rendement du maïs (Milleville et al., 2000) (Fig. 4). L'étude de la dynamique post-culturale de la végétation et du milieu édaphique, conduite sur une série d'abandons culturaux de 2 à 30 ans, montre que d'importants changements apparaissent dans la succession, marquée par une régression 


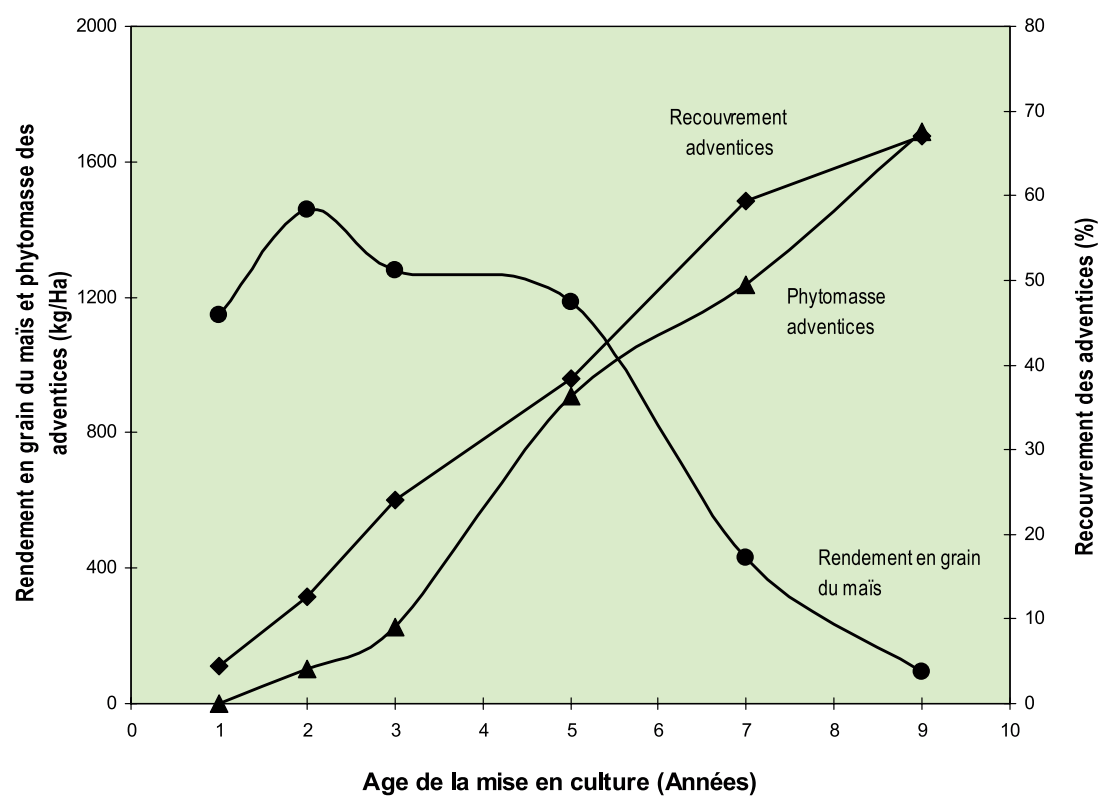

Fig. 4. Variations du rendement en grain du maïs, de la phytomasse et du recouvrement des adventices en fonction de l'ancienneté de la mise en culture au cours du cycle 1997-1998.

progressive de la richesse floristique (Grouzis et al., 2001). L'examen des trajectoires, établies à l'aide d'une analyse multivariée des paramètres biologiques et édaphiques, indique que l'évolution de la végétation après 30 ans conduit à une formation mixte ligneux-herbacées, ouverte, à caractère savanicole, contrairement à ce qui prévaut dans les systèmes d'abattis-brûlis des zones tropicales humides, caractérisés par une dynamique de reconstitution forestière au cours de la phase postculturale. Ainsi, dans les zones humides de l'Est et du Nord-Ouest de Madagascar, la culture sur abattis-brûlis (tavy) repose principalement sur le riz pluvial. La brièveté de la phase culturale (2 ans en général) et la forte résilience des systèmes forestiers y conduisent à une dynamique de reforestation (Rasolofoharinoro et al., 1997; Gautier et al., 1999; Aubert et al., 2003). De ce fait, des tavy peuvent être ouverts sur les mêmes sites après de longues périodes de jachères arbustive et arborée. Dans le SudOuest, au contraire, la durée beaucoup plus longue de la phase de culture (5 à 8 ans), les conditions climatiques et édaphiques plus drastiques et la très faible résilience des forêts induisent une dynamique post-culturale de savanisation.

- Les agronomes se sont attachés, d'une part, à l'étude de la conduite des systèmes de culture (Milleville et Blanc-Pamard, 2001) ainsi qu'à l'évolution et à la variabilité des rendements du maïs (Milleville et al., 2001), d'autre part, au fonctionnement des unités de production familiales sur les fronts pionniers.

1. Les premiers de ces travaux ont été menés selon différentes procédures d'enquête et d'expérimentation. $\mathrm{Au}$ cours de la phase culturale, longue de 5 à 8 ans ou plus, le rendement en grain du maïs subit une chute sensible dès la troisième ou quatrième année, en raison de la pression croissante des adventices et de la dégradation des paramètres physico-chimiques de la fertilité des sols. De l'ordre de 1500 kg/ha durant les premières années de culture, les rendements se situent ainsi à des niveaux généralement inférieurs à $500 \mathrm{~kg} /$ ha à partir de la cinquième année, tandis que les besoins en travail augmentent et qu'il devient difficile de contrôler efficacement l'enherbement dans ce contexte de culture manuelle extensive. Les paysans préfèrent donc abandonner plus ou moins précocement les sites de culture et poursuivre plus avant les défrichements, afin de maintenir à un niveau élevé la productivité de leur travail (la dépense en travail à l'unité de surface étant très limitée durant les premières années de culture) et de s'assurer pour l'avenir d'un contrôle foncier sur de grands espaces. Néanmoins, l'éloignement progressif vers l'ouest des fronts de défrichement pousse de plus en plus d'agriculteurs à remettre en culture d'anciens abandons, mais à l'aide d'autres techniques que celles de l'abattisbrûlis. En effet, le maintien d'une strate herbacée dans les friches explique que le hatsaky ne constitue pas un système de culture durable en tant que tel (Milleville et al., 2001). Il caractérise seulement la première étape, celle de la conquête pionnière de l'espace forestier. Plusieurs essais montrent qu'un travail du sol et une fertilisation légère permettent d'obtenir, lors de la remise en culture des friches, des rendements très satisfaisants en arachide et en maïs.

2. La caractérisation et la catégorisation des unités de production sur les fronts pionniers ont été réalisées 
par des enquêtes portant sur l'histoire de l'unité de production et de la famille, la constitution actuelle du système de production et les perspectives envisagées par l'agriculteur et sa famille (Aubry et Ramaromisy, 2003). Neuf types de fonctionnement ont pu être distingués, à partir de plusieurs critères, dont :

- La taille de l'exploitation et son inscription dans le territoire : de moins de 5 à plus de 100 ha, les exploitations sont généralement bipolaires, un pôle étant situé en front pionnier, avec comme seule culture le maïs sur abattis-brûlis, l'autre sur des terres anciennement défrichées (et partiellement remises en culture avec manioc et maïs) à proximité des habitations. Certaines exploitations possèdent aussi des cultures (coton en particulier) sur les terres d'origine alluviale (baiboho), mises en valeur depuis longtemps à l'est de la RN9.

- L'importance du troupeau bovin : les troupeaux bovins sont peu nombreux, sauf dans deux types d'exploitations de grande taille, les autres n'ayant au mieux qu'un troupeau réduit à moins de 5 têtes. Les terres en friches sont considérées comme espace pastoral par les possesseurs de troupeaux. Par ailleurs, l'attelage et les bœufs de trait, fort utiles pour le transport de l'eau et des récoltes, existent systématiquement dans plusieurs types d'exploitations ; ils sont minoritaires, voire exceptionnels, dans d'autres.

- La main-d'œuvre mobilisable : elle est la clé de la capacité de défriche d'une exploitation ${ }^{6}$ : les plus gros défricheurs sont ceux qui peuvent avoir accès, du fait de leurs capacités financières, à une main-d'œuvre salariée temporaire importante pendant la saison sèche.

Le suivi d'un échantillon d'unités de production durant une année montre de grandes disparités quant à la part du maïs dans l'alimentation familiale, aux revenus monétaires et au temps de travail. Par ailleurs, le hatsaky ne constitue jamais la seule activité des exploitants : salariat agricole dans les plus grosses exploitations, coupe de bois en forêt, petit commerce et transport, voire vente de produits forestiers de chasse et de cueillette, représentent des sources de revenus souvent plus importantes.

La connaissance des unités de production donne accès, de façon organisée, à la diversité des acteurs de la déforestation et permet d'identifier les catégories de défricheurs les plus actifs : 45 à $55 \%$ de la surface défrichée annuellement sur l'ensemble de la commune d'Analamisampy, qui regroupe quelque 20000 habitants, serait ainsi le fait de 17 à 20 gros producteurs.

\footnotetext{
${ }^{6}$ En moyenne, un homme seul défriche entre 2,5 et 3 ha par mois en travaillant à temps plein.
}

- Les études géographiques ont traité de l'histoire du peuplement, des stratégies d'acteurs, de leurs perceptions et représentations, de l'organisation du paysage. Dans la mesure où la déforestation est bien visible dans le paysage, celui-ci tient une place importante, $\mathrm{d}$ 'une part comme expression du réel (d'où l'utilité de l'imagerie aérienne et satellitaire), de l'autre comme construction sociale, résultat des interactions entre dynamiques écologiques, techniques et sociales. L'étude a concerné plus particulièrement Analabo, un terroir d'agriculture extensive en situation pionnière, et les villages et campements que ses habitants ont créés (Fig. 3). La pratique du hatsaky a produit, sur de grandes étendues, un paysage très particulier qui ne cesse d'étonner par son ampleur et sa répétitivité. L'espace défriché se structure à travers les représentations que se font les protagonistes de la dynamique et de l'orientation des essarts qui les concernent directement. On assiste, en forêt, à l'émergence d'un territoire dès lors que la société attribue à cet espace des toponymes associés à la pratique des défrichements.

La recherche a porté sur les aspects dynamiques de l'occupation du sol, plus particulièrement sur la progression du front de culture et les arrangements spatiaux qui en découlent, en associant l'analyse des dynamiques agraires à celle des mécanismes sociaux. Les membres des clans fondateurs jouent un rôle de premier plan pour l'accès à la forêt, car ce sont eux les tompon-tany (maîtres de la terre), et c'est à eux que s'adressent les nouveaux venus pour se faire attribuer une portion de forêt. L'histoire du village d'Ampasikibo, créé en 1922, est riche d'enseignements sur la dynamique pionnière. Un travail sur la généalogie du clan fondateur Lazafara permet de suivre la dynamique de l'organisation de l'espace, de repérer les modalités d'accueil et d'installation des étrangers et de mesurer le jeu des alliances matrimoniales (Blanc-Pamard et Rebara, 2001). Les villages et campements créés au cours du temps se sont structurés par les liens de parenté, puis se sont développés par des relations matrimoniales dans un objectif de consolidation d'un territoire en forêt. Les pratiques sociales des clans fondateurs témoignent de l'efficacité du système dans le contrôle et la construction d'un territoire. Cet ordre social, que cherchent à instaurer les premiers occupants, rencontre les appétits d'autres exploitants expansionnistes, agroéleveurs le plus souvent, qui leur disputent l'espace disponible à l'intérieur de leur territoire.

La figure 5 résume une séquence historique : celle de la construction du territoire, de 1922 à 2001, à partir d'Ampasikibo puis d'Analabo. Soit six périodes, de la mise en valeur commencée en savane dans les années 1920 avec l'élevage, puis le pois du Cap et le coton, à l'exploitation de la forêt pour le bois puis, dès les années 1970, pour la culture du maïs sur abattis-brûlis. Les premiers villages se sont installés le long de la RN9 dans les années 1920. Ils ont commandé eux-mêmes d'autres 

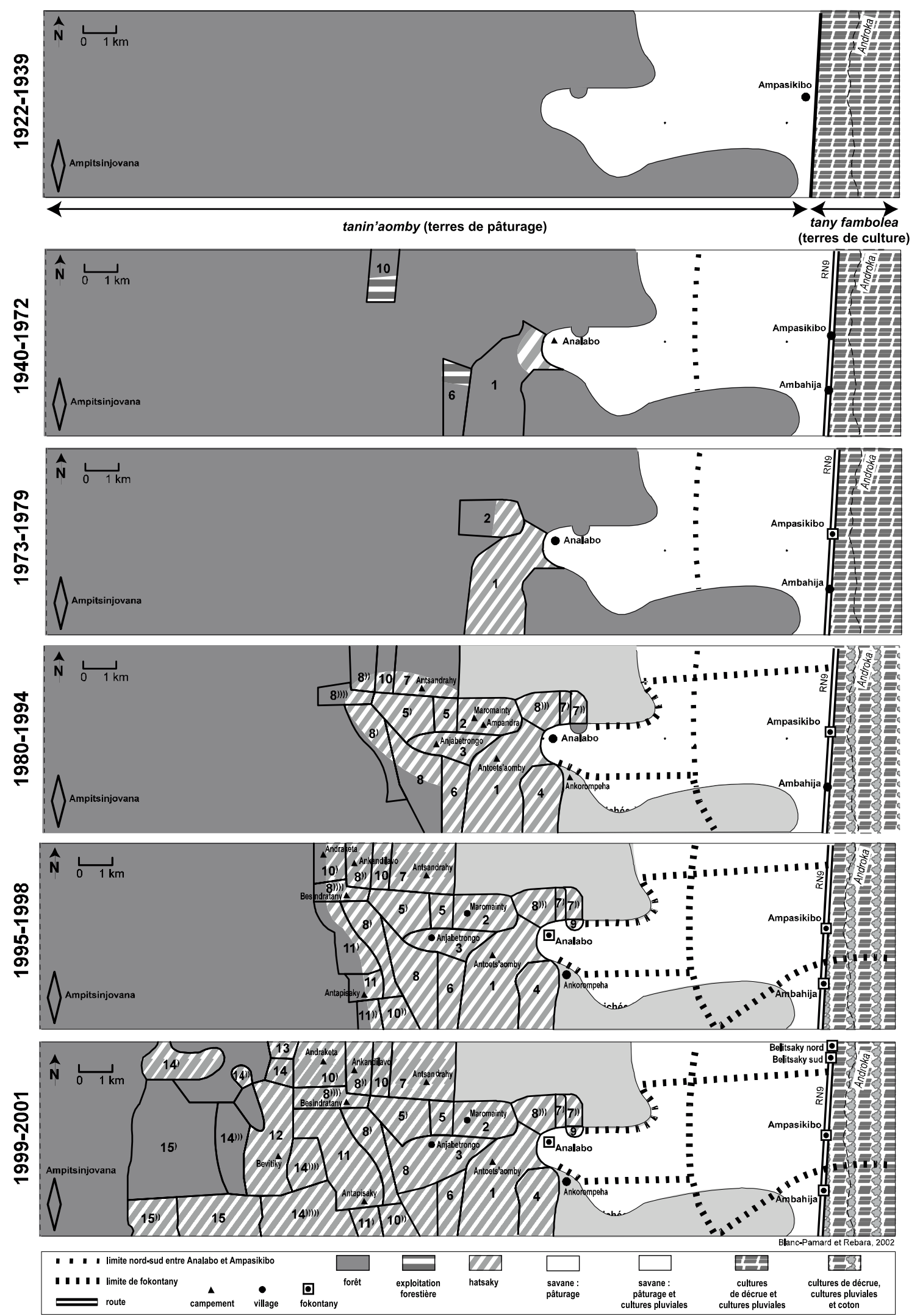

Fig. 5. Ampasikibo et Analabo : la construction du territoire de 1922 à 2001. 
établissements, orientés vers l'élément essentiel que représente la forêt à l'ouest, qui, à leur tour, ont fondé des campements. Le front de défrichement est situé en 2001 à $18 \mathrm{~km}$ de la RN9 contre $7 \mathrm{~km}$ en 1973. Les habitants des fronts pionniers représentent $13 \%$ de la population totale de la commune rurale d'Analamisampy.

Une stratégie obsédante de course à la forêt, une poursuite de la culture du maïs sur les hatsaky pendant quatre, cinq années, voire plus, et l'amorce d'une agriculture permanente sur les terres conquises en forêt sont, en 2001, les caractères principaux de la dynamique du système agraire en forêt. Dans la mesure où le défrichement vaut appropriation du sol, sur le front pionnier où les terres sont en accès libre, les stratégies vont bon train. Les défrichements se poursuivent toujours plus loin à l'ouest, mais la pénétration en forêt se traduit par de lourdes contraintes, comme l'éloignement croissant de la RN9 et des points d'eau permanents. L'accès inégal à la forêt est devenu un facteur de différenciation entre exploitants. La perturbation environnementale forte que constitue la destruction de la forêt s'accompagne d'une recomposition des rapports sociaux, économiques et fonciers.

Cette étude géographique, localisée à l'échelle d'un terroir, a été élargie, par des enquêtes extensives, à d'autres fronts pionniers, dans les limites de la commune rurale et hors de celle-ci, afin d'appréhender l'ampleur du phénomène d'agriculture sur abattis-brûlis, son avenir, ses acteurs (autochtones et migrants) et leurs stratégies, les réponses apportées à la fin prochaine de la forêt " utile» (Blanc-Pamard et Rebara, 2002; Blanc-Pamard, 2002a).

- La géomatique permet, à partir de l'imagerie satellitale, le repérage, l'identification et la cartographie des différents faciès de végétation (naturels et cultivés) et constitue, par ailleurs, un outil très intéressant pour rendre compte par des analyses diachroniques de l'extension spatiale des phénomènes, et en particulier de la quantification des surfaces et des vitesses de déforestation au cours des 30 dernières années. L'étude a porté sur l'ensemble du front actif de la forêt, soit une zone de $751 \mathrm{~km}^{2}$ définie à l'ouest par la limite de la forêt considérée comme exploitable pour l'agriculture. Les images utilisées ont été des SPOT HRV Xs multidates (image de 2001 en programmation et les autres en archive), toutes acquises en fin de saison des pluies à l'optimum de végétation. Les données de terrain correspondent aux observations réalisées sur les segments d'enquête, principalement types de végétations, couleur et type de sol, recouvrement (sol nu, strates herbacée et ligneuse) et degré d'artificialisation, couplées à des relevés GPS. Parallèlement, une mission de photographies aériennes à basse altitude (paramoteur) a été conduite. L'identification des faciès a alors été effectuée pour établir une cartographie précise de l'occupation du sol et de la limite forestière pour l'année 2001. L'évolution du front de défrichement
Tableau 1. Surfaces forestières, surfaces défrichées et vitesse annuelle de déforestation à quatre périodes.

\begin{tabular}{cccrc}
\hline $\begin{array}{c}\text { Période de } \\
\text { défrichement }\end{array}$ & $\begin{array}{c}\text { Surface } \\
\text { forestière } \\
\left(\mathrm{km}^{2}\right)\end{array}$ & $\begin{array}{c}\text { Surface } \\
\text { défrichée } \\
\left(\mathrm{km}^{2}\right)\end{array}$ & $\%$ & $\begin{array}{c}\text { Vitesse } \\
\text { annuelle de } \\
\text { défrichement } \\
\left(\mathrm{km}^{2} / \mathrm{an}\right)\end{array}$ \\
\hline $1971-1986$ & 751 & 88,07 & 11,7 & 5,87 \\
$1986-2001$ & 664,6 & 289,5 & 43,6 & 19,3 \\
$1997-1999$ & 486,3 & 41,39 & 8,5 & 20,69 \\
$1999-2001$ & 444,9 & 69,72 & 15,7 & 34,86 \\
\hline
\end{tabular}

en 1971 et 2001 est représentée sur la figure 2. Le tableau 1 enregistre les surfaces défrichées et les vitesses de déforestation à différentes périodes. Ces travaux de géomatique ont été conduits en étroite collaboration avec l'écologie, l'agronomie et la géographie.

Si chacun construit son propre objet de recherche, le souci d'aborder des objets conjoints, à l'interface de plusieurs disciplines, impose néanmoins, pour partie, le choix de sites communs et une certaine uniformisation des échelles de travail et des rythmes de collecte de l'information. Par-delà la spécificité des questions et des approches, la référence à l'espace permet aux différentes disciplines de prendre la mesure de leurs objets d'étude en termes de localisation, d'extension et de dynamique spatiotemporelle des phénomènes. À ce titre, l'imagerie satellitale constitue un matériau précieux de dialogue et de confrontation des résultats.

\section{Territoires, nouveaux objets, nouvelles méthodes}

\section{Des évaluations convergentes : savoirs de chercheurs et savoirs locaux}

Les diagnostics scientifiques, établis à travers les grilles de caractérisation des chercheurs, rejoignent assez précisément les nomenclatures et perceptions paysannes. Cela concerne la reconnaissance des différents types de sols et de formations végétales "naturelles » (éléments relativement stables du milieu) ainsi que des objets qui évoluent plus ou moins vite au cours du temps (cultures récentes/anciennes en rapport avec l'abondance des adventices, classes d'abandons culturaux). Les dénominations paysannes, de par leur validation, constituent aussi des outils de catégorisation communs à plusieurs disciplines qui sont en outre opératoires dans leur démarche.

Dans le système de culture sur abattis-brûlis, la variable-clé est l'âge de la parcelle. La plupart des agriculteurs désignent par hatsabao les deux premières années qui ne nécessitent aucun sarclage, et par mondra les années suivantes, où le contrôle des adventices est reconnu comme nécessaire. À travers leurs grilles d'observation, l'agronome et l'écologue confirment que l'envahissement 


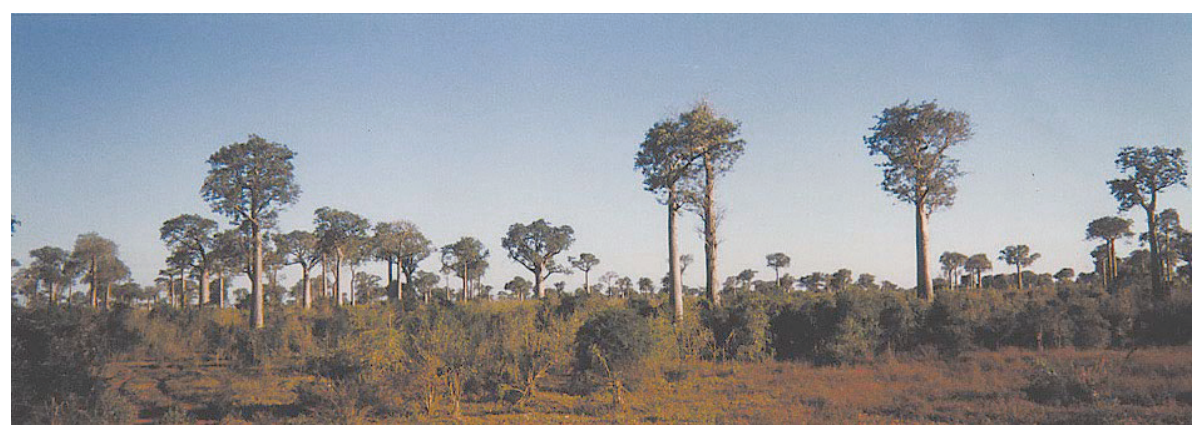

Photo. 2. Friche d'une trentaine d'années (photo C. Blanc-Pamard).

par les adventices devient effectivement sensible dès la troisième année de culture, et qu'il augmente ensuite progressivement. Un travail à l'échelle de la forêt des Mikea (Blanc-Pamard et Rebara, 2002) signale des variations dans la dénomination des stades du cycle cultural et dans la durée de la phase culturale suivant la forme et l'intensité que prennent localement les défrichements. Cette terminologie non encore fixée témoigne probablement d'une histoire agraire récente ainsi que d'éventuelles variations locales des conditions de milieu. À ce titre, on peut constater que sur les affleurements calcaires, où la prolifération des mauvaises herbes est plus rapide que sur sables, le terme d'hatsabao est réservé à la première année de culture. À travers un tel exemple, on perçoit comment la pratique et le discours des paysans contribuent à l'identification d'objets scientifiques communs qui permettent une collaboration entre différentes disciplines.

\section{Changements techniques, processus écologiques et dynamiques sociales}

Dans de telles situations pionnières, le temps construit le territoire. Celui-ci est en perpétuelle mouvance, se transformant dans ses limites, son contenu, son organisation et sa fonctionnalité. Ses utilisateurs, agents de ces transformations, doivent aussi s'y adapter, en modifiant leurs pratiques et/ou en introduisant de nouveaux changements territoriaux, dans un contexte de forte incertitude et de déficit de références. Une perspective temporelle s'impose donc à toutes les disciplines, les conduisant à retenir des modalités de découpage du temps et de l'espace fondées sur les pratiques des acteurs et les dynamiques du milieu. Le front pionnier est affaire de vitesses et aussi de durées, de pas de temps différents : itinéraire de défriche, phase culturale et évolution du milieu cultivé, phase post-culturale et processus de savanisation, progression des fronts pionniers et du peuplement... La recherche, poursuivie sur plusieurs années, permet de saisir les différentes dynamiques dans leurs manifestations et leurs processus, et d'en reconstituer les étapes et la transcription spatiale sur de plus longues durées (plusieurs décennies).
Au cours du temps, l'emprise spatiale des abandons culturaux s'est considérablement accrue (Photo 2). Ils deviennent un nouvel objet de recherche, dans la mesure où des enjeux décisifs leur sont liés. En effet, chacun perçoit que les possibilités de poursuite des défrichements en forêt se raréfient, avec l'éloignement des fronts de défrichement et la péjoration des conditions de culture du maïs (sols de plus en plus pauvres, pluviométrie limitée). L'avenir réside donc, pour la plupart des paysans, dans la reprise des friches, afin $\mathrm{d}^{\prime} \mathrm{y}$ installer des systèmes de culture durables. Mais les agriculteurs manquent de références techniques sur cette question, et sont conduits à expérimenter différentes modalités techniques permettant de cultiver ces friches en assurant un contrôle satisfaisant de l'enherbement sans dépense en travail excessive. La pratique du paillage déjà expérimentée par certains paysans, ainsi que les techniques de semis direct sous couvert, telles que les préconisent des acteurs de développement régional ${ }^{7}$, pourraient constituer sous certaines conditions des alternatives au travail du sol, qui reste encore la méthode couramment adoptée pour assurer le contrôle de l'enherbement. La recherche se trouve de ce fait impliquée dans la mise au point d'alternatives techniques (conception de systèmes de culture), mais aussi dans les options de gestion future de ces espaces (organisation territoriale des activités agricoles et pastorales).

La prise en compte du temps a constitué à l'évidence un élément déterminant de cette recherche. Chaque chercheur, quelle que soit sa discipline, s'est trouvé confronté à des objets en mutation profonde et a donc été conduit à évaluer des changements et à expliciter des processus en y accordant sans aucun doute plus d'attention qu'à la compréhension synchronique de ces situations. Par ailleurs, c'est progressivement autour des évolutions à venir et des perspectives d'action et de gestion que se sont orientés, en cours de programme, les efforts de recherche. Autrement dit, il convient de ne plus s'en tenir à l'analyse des changements passés ou observables, mais aussi d'accompagner les changements en cours et à venir,

\footnotetext{
${ }^{7}$ Le projet Sud-Ouest (PSO) avec l'ONG TAFA a contribué à tester et diffuser ces techniques dans la région de Tuléar depuis le milieu des années 1990.
} 
dans des espaces de référence reconnus pertinents tant pour les chercheurs que pour les usagers.

\section{Recompositions territoriales}

Compte tenu de ces dynamiques, la configuration territoriale se transforme profondément. La zone de baiboho située à l'est, affectée depuis longtemps par une forte saturation foncière, n'évolue qu'à travers l'importance relative qu'y tiennent les différentes cultures ${ }^{8}$ et le contrôle foncier exercé respectivement par les petites exploitations et les gros producteurs. À l'ouest de la RN9, par contre, les changements apparaissent radicaux, avec la disparition des espaces forestiers, le déplacement des hatsaky, l'expansion des abandons culturaux, la création de blocs de cultures en savanes. À l'échelle de la commune d'Analamisampy, la superficie de forêt défrichée depuis une trentaine d'années peut être estimée en 2001 à $237 \mathrm{~km}^{2}$ (soit $32 \%$ de la surface du territoire communal), se répartissant en $48 \mathrm{~km}^{2} \mathrm{~d}$ 'abandons culturaux anciens, $115 \mathrm{~km}^{2}$ d'abandons culturaux récents, $27 \mathrm{~km}^{2}$ de hatsaky anciens et $47 \mathrm{~km}^{2}$ de hatsaky récents (Photo 3). Il en résulte une expansion de l'ordre de $58 \%$ de l'espace pastoral (les terres de culture pouvant être fréquentées par les troupeaux durant la saison sèche, les friches comme les savanes l'étant toute l'année). Cette transformation territoriale ne concerne que les fokontany de l'ouest, qui profitent de parcours beaucoup plus étendus que par le passé, et donc d'une possibilité, au moins théorique, d'accroissement important de leur cheptel. Ceux de l'est, par contre, conservent quasiment le même espace de parcours que par le passé. On pouvait ainsi évaluer, en 2001, les surfaces de parcours disponibles (incluant les zones de culture) à 2,5 hectares par tête de bovin à l'est, et à 4,6 hectares par tête à l'ouest.

La référence au territoire communal s'est, on le voit, peu à peu imposée à l'équipe de recherche. Il convenait d'abord d'élargir l'espace de référence initial, le fokontany d'Analabo, à la commune rurale d'Analamisampy (Fig. 3) afin de valider les résultats acquis et de prendre en considération d'autres situations, différant de la première par les conditions de milieu ou/et les aspects sociodémographiques et l'histoire de la dynamique pionnière. Il était en outre indispensable d'appréhender les phénomènes étudiés sur des espaces d'activité de communautés clairement identifiables. Le territoire communal représente à cet égard une entité d'importance particulière, intermédiaire entre le terroir et la région. Depuis la décentralisation mise en place en 1995, la commune, constituée d'un ensemble de fokontany, représente un cadre territorial conçu comme un territoire de projets. C'est un niveau local de participation, d'initiative et de prise de

\footnotetext{
${ }^{8}$ La crise que traverse la filière cotonnière se traduit depuis plusieurs années par une réduction sensible des surfaces consacrées au coton.
}

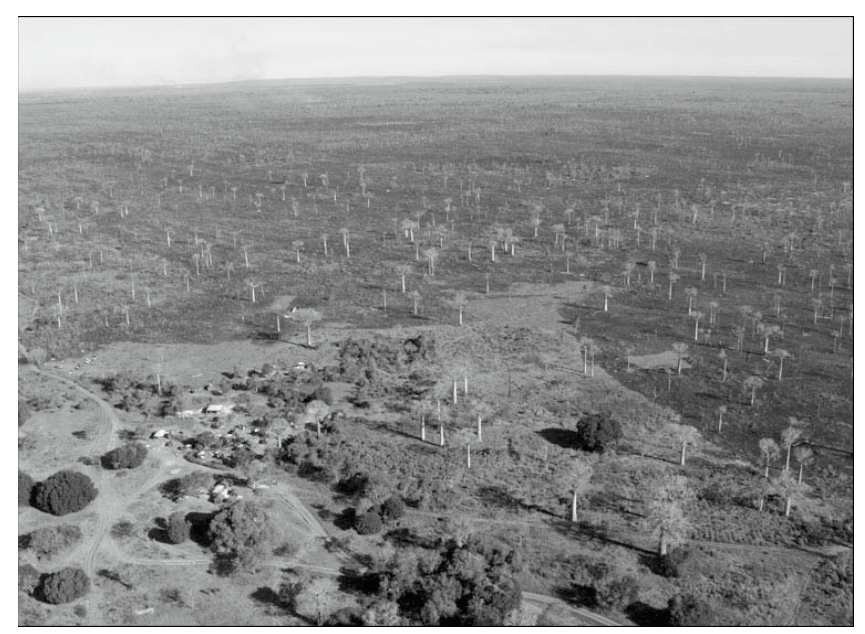

Photo. 3. Parc à baobabs (Adansonia za) résiduel (photo (c) Gerem-CNRE/IRD).

décision par les acteurs locaux pour définir et mettre en place des projets de développement rural et des actions de gestion et de conservation des ressources naturelles renouvelables. Il nous est donc apparu nécessaire, à cette échelle spécifique, de collecter des compléments d'information, de réaliser des bilans, et de constituer un système d'information géographique (SIG) prenant notamment en compte les faits de peuplement et d'occupation des terres. Ce travail, par nature interdisciplinaire, a été réalisé en phase finale du programme et a largement profité des connaissances acquises antérieurement. Un ensemble de cartes thématiques $\left(1 / 100000^{\mathrm{e}}\right)$ constitue pour l'équipe de recherche un cadre privilégié de partage des connaissances, un niveau d'analyse spécifique et un outil-relais à partir duquel de nouvelles opérations de recherche deviennent possibles. Ces documents représentent par ailleurs, pour les acteurs locaux, une source d'information précieuse, utile à la prise de décision. Il reste que, dans un contexte affecté de dynamiques aussi rapides et massives, les données deviennent vite obsolètes, et que se pose donc la question cruciale de leur actualisation.

Par ailleurs, l'équipe GEREM a souhaité poursuivre le travail collectif entrepris pour la constitution d'un SIG par la fabrication d'un CD-ROM (Lasry et al., à paraître). C'est un outil de synthèse et de valorisation des recherches : il fournit aux chercheurs, aux acteurs du développement, aux gestionnaires de l'environnement et à tout professionnel impliqué dans les thématiques abordées une base de données très riche sur une partie de la région du Sud-Ouest. Avec ce CD-ROM, l'équipe se positionne dans une approche «systèmes d'information ». Le CD-ROM amplifie le rôle de la carte et de toute représentation spatiale (carte, croquis, image satellitalle, photographie aérienne...). Plus encore, il semble que toute l'iconographie disponible dans le CD-ROM permette une rencontre et puisse aider à construire un dialogue entre chercheurs, décideurs et acteurs locaux dans un objectif 
de développement et d'environnement. L'intérêt du CDROM réside dans la place qui est faite à l'outil cartographique (cartes thématiques au $1 / 100000^{\mathrm{e}}$ et cartes à différentes échelles). La carte permet de communiquer, $\mathrm{d}$ 'accompagner, voire de susciter des négociations entre les divers partenaires.

\section{Conclusion}

Par le passé, les disciplines des sciences de la nature (écologie), des sciences biotechniques (agronomie) et des sciences de la société (géographie) se sont rarement rencontrées aux mêmes échelles d'observation. Avec les questions d'environnement, de telles alliances s'imposent. Ces questions entraînent en effet un repositionnement des disciplines sur d'autres bases que celles $\mathrm{d}^{\prime}$ une dichotomie entre les domaines de l'agraire et $\mathrm{du}$ rural, d'une part, et ceux de la nature, d'autre part (Jollivet, 1992; Benoit et Papy, 1998; Lescure, 1997; Milleville et al., 2000). Les alliances s'imposent dans ce type de conception de l'environnement, où l'on est amené à prendre en compte les relations entre des espaces et des types de milieux très contrastés de par leur niveau d'artificialisation, d'une part parce qu'ils coexistent dans des territoires contrôlés et gérés par des collectivités et que, d'autre part, ils entretiennent entre eux des relations de filiation à travers des dynamiques temporelles. Les relations dynamiques qui existent entre ces types de milieux font qu'il devient artificiel d'aborder les problèmes environnementaux d'une manière autonome pour chacun d'entre eux. Cette étude plaide donc pour une approche temporelle et territorialisée des problèmes d'environnement, d'où l'exigence transdisciplinaire.

Le programme GEREM, via la collaboration entre ces disciplines, a fait émerger la déforestation comme un problème d'environnement, au sens où les connaissances scientifiques acquises donnent l'alerte sur l'ampleur du phénomène, son caractère irréversible et sur la perte de biodiversité qui en résulte. Les acteurs de cette déforestation, quant à eux, qui considèrent la forêt comme une ressource quasi illimitée, ne traduisent dans leurs discours et leurs pratiques que des préoccupations liées aux difficultés de la mise en valeur de cette ressource. Un tel décalage entre les représentations d'un problème est source de réflexion commune sur le temps et la notion de développement durable.

Un problème d'environnement n'est pas en soi une question de recherche. S'y intéresser implique d'identifier des questions de recherche disciplinaires, puis de les mettre en commun pour révéler de nouveaux objets pertinents pour l'action (Hubert, 2001). Ceux-ci apparaissent orientés vers la recherche concertée de solutions à des problèmes complexes d'environnement. Pour l'agronomie et l'écologie, il convient ainsi de ne pas s'en tenir aux échelles de la station et de la parcelle, mais d'aborder aussi le devenir des phases culturale et post-culturale dans leurs dimensions spatiales, et d'apprécier à l'échelle territoriale les alternatives de type intensif/extensif et la question de la durabilité.

La notion de territoire s'est donc imposée progressivement à l'ensemble de l'équipe de recherche. S'il constitue un objet d'évidence de la géographie (et ce, dès l'engagement de la recherche), il n'en va pas de même en écologie et en agronomie, lorsque priorité est donnée à la compréhension de processus et de comportements que l'on peut appréhender à l'échelle locale. Le souci de spatialisation des phénomènes résulte alors souvent $\mathrm{d}$ 'une étape ultérieure de la recherche, visant à prendre la mesure de leur importance, ainsi qu'à valider à d'autres échelles les résultats établis localement. La notion de territoire traduit enfin, au-delà de la spatialisation, la reconnaissance du rôle et de la place des acteurs dans l'exploitation et la dynamique des milieux. On peut donc légitimement s'interroger sur le bien-fondé de politiques purement protectionnistes qui, face à la déforestation galopante, n'ont d'autres solutions à proposer que la création d'aires protégées dont sont exclus en grande partie les acteurs locaux.

Le double processus d'émergence d'un problème d'environnement et de sa traduction en questions de recherche caractérise la posture adoptée dans le programme GEREM. C'est bien le couplage agraireenvironnement, ainsi que la combinaison des notions de temps et de territoire, qui ont permis, au sein de l'équipe de recherche, la mise en commun de questions scientifiques et la conception de produits d'interface disciplinaire.

\section{Références}

Aubert, S., Razafiarison, S., Bertrand, A., 2003. Déforestation et systèmes agraires à Madagascar. Les dynamiques des tavy sur la côte orientale, Montpellier/Antananarivo, CIRAD/CITE/FOFIFA.

Aubry, C., Ramaromisy, A., 2003. Typologie d'exploitations agricoles dans un village du front pionnier de la forêt des Mikea (Sud-Ouest de Madagascar), Cahiers Agricultures, 12, 153-165.

Benoit, M., Papy, F., 1998. La place de l'agronomie dans la problématique environnementale, Les Dossiers de l'environnement de l'INRA, 17, 53-62.

Blanc-Pamard, C., 2000. À l'ouest d'Analabo. La trame du maïs. Agriculture pionnière et construction $d u$ territoire en pays masikoro (Sud-Ouest de Madagascar), GEREM/IRD/CNRE, CNRS/EHESS.

Blanc-Pamard, C., Rebara, F., 2001. L'école de la forêt : dynamique pionnière et construction du territoire, in Razanaka, S., Grouzis, M., Milleville, P., Moizo, B., Aubry, C. (Eds), Sociétés paysannes, transitions agraires et dynamiques écologiques dans le Sud-Ouest de Madagascar, Antananarivo, IRD/CNRE. 
Blanc-Pamard, C., Rebara, F., 2002. Paysans de la commune d'Analamisampy. Dynamiques sociales et transitions agraires en pays masikoro (Sud-Ouest de Madagascar), GEREM/IRD/CNRE, CNRS/EHESS.

Blanc-Pamard, C., 2002a. Territoire et patrimoine dans le SudOuest de Madagascar : une construction sociale, in CormierSalem, M.-C., et al. (Eds), Patrimonialiser la nature tropicale, IRD Éditions.

Blanc-Pamard, C., 2002b. La forêt et l'arbre en pays masikoro (Madagascar) : un paradoxe environnemental ?, Bois et forêts des Tropiques, 271, 5-22.

Gardette, Y.-M., 1997. Évaluation historique et économique de l'exploitation du bois d'cuvre dans la région de Tuléar (Madagascar). Mémoire ORSTOM-MAA et MRAQ-CNRE, Université de Paris 10 - Nanterre.

Gautier, L., Chatelain, C., Spichiger, R., 1999. Déforestation, altitude, pente et aires protégées : une analyse diachronique des défrichements sur le pourtour de la réserve spéciale de Manongarivo (N-O Madagascar), in Hurni, H., Ramamonjisoa, J. (Eds), African Mountain Development in a changing world, African Mountains Associations, 255-279.

Grouzis, M., Razanaka, S., 2001. Aspects qualitatifs et quantitatifs de l'évolution des adventices en fonction de la durée de la mise en culture dans les systèmes de culture sur abattisbrûlis d'Analabo, in Razanaka, S., Grouzis, M., Milleville, P., Moizo, B., Aubry, C. (Eds), Sociétés paysannes, transitions agraires et dynamiques écologiques dans le Sud-Ouest de Madagascar, Antananarivo, IRD/CNRE, 269-279.

Grouzis, M., Razanaka, S., Le Floc'h, E., Leprun, J.-C., 2001. Évolution de la végétation et de quelques paramètres édaphiques au cours de la phase post-culturale dans la région d'Analabo, in Razanaka, S., Grouzis, M., Milleville, P., Moizo, B., Aubry, C. (Eds), Sociétés paysannes, transitions agraires et dynamiques écologiques dans le Sud-Ouest de Madagascar, Antananarivo, IRD/CNRE, 327-337.

Hubert, B., 2001. Évolution du questionnement de la recherche par les problèmes environnementaux, in Razanaka, S., Grouzis, M., Milleville, P., Moizo, B., Aubry, C. (Eds), Sociétés paysannes, transitions agraires et dynamiques écologiques dans le Sud-Ouest de Madagascar, Antananarivo, IRD/CNRE, 361-369.

Humbert, H., Cours-Darne, G., 1965. Notice de la carte de Madagascar, Travaux sect. Sci. et Techn., Institut français de Pondichéry, h.s., 6, 46-78.

Jollivet, M. (Ed.), 1992. Sciences de la nature, sciences de la société. Les passeurs de frontières, Paris, CNRS Éditions.

Koechlin, J., Guillaumet, J.-L., Morat, P., 1974. Flore et végétation de Madagascar, Vaduz, J. Cramer.

Lasry, F., Grouzis, M., Milleville, P., Razanaka, S., 2004. Dynamique de la déforestation et agriculture pionnière dans une région semi-aride du Sud-Ouest de Madagascar : exploitation diachronique de l'imagerie satellitale haute résolution, Photo-Interprétation, 1, 26-33.

Lasry, F., Blanc-Pamard, C., Milleville, P., Razanaka, S., Grouzis, M. (Eds), à paraître. Environnement et pratiques paysannes à Madagascar, CD-ROM, IRD Éditions.

Leprun, J.-C., 1998. Compte rendu de mission à Madagascar (projet GEREM), Anatananarivo, ORSTOM-CNRE.
Lescure, J.-P., 1997. Ruralité ou environnement?, in La Ruralité dans les pays du Sud à la fin $d u X X^{e}$ siècle, Paris, ORSTOM Éditions.

Milleville, P., Grouzis, M., Razanaka, S., Razafindrandimby, J., 2000. Systèmes de culture sur abattis-brûlis et déterminisme de l'abandon cultural dans une zone semi-aride du SudOuest de Madagascar, in Floret, C., Pontanier, R. (Eds), La Jachère en Afrique tropicale : rôles, aménagement, alternatives, Actes du Séminaire international, Dakar, 13-16 avril 1999, Paris, John Libbey Eurotext, 59-72.

Milleville, P., Blanc-Pamard, C., 2001. La culture pionnière de maïs sur abattis-brûlis (hatsaky) dans le Sud-Ouest de Madagascar. 1. Conduite des systèmes de culture, in Razanaka, S., Grouzis, M., Milleville, P., Moizo, B., Aubry, C. (Eds), Sociétés paysannes, transitions agraires et dynamiques écologiques dans le Sud-Ouest de Madagascar, Antananarivo, IRD/CNRE, 243-254.

Milleville, P., Grouzis, M., Razanaka, S., Bertrand, M., 2001. La culture pionnière du maïs sur abattis-brûlis (hatasky) dans le Sud-Ouest de Madagascar. 2. Évolution et variabilité des rendements, in Razanaka, S., Grouzis, M., Milleville, P., Moizo, B., Aubry, C. (Eds), Sociétés paysannes, transitions agraires et dynamiques écologiques dans le Sud-Ouest de Madagascar, Antananarivo, IRD/CNRE, 255-268.

Raherison, S. M., 2000. Écosystème forestier de la région d'Analabo (forêt de Mikea) sur sables roux clairs : structure, production et réserve en eau du sol. DEA, Département de Biologie et d'Écologie végétales, Université d'Antananarivo, co-encadrement GEREM, CNRE-IRD.

Raherison, S. M., Grouzis, M., à paraître. Plant biomass, nutrient concentration and nutrient storage in a tropical dry forest in the South-West of Madagascar, Plant Ecology.

Rakotojaona, H., 2000. Écosystème forestier de la région d'Analabo (forêt de Mikea) sur sables roux foncés : diversité, structure et dynamique de l'eau dans le sol. DEA, Département de Biologie et d'Écologie végétales, Université d'Antananarivo, co-encadrement GEREM, CNRE-IRD.

Rakotojaona, H., Grouzis, M., 2005. Diversité floristique, structure et phytomasse d'un écosystème forestier du sudouest malgache (forêt des Mikea), in Recueil d'articles pour le suivi du Programme Environnemental, ONE, Antananarivo (accepté).

Rasolofoharinoro, M., Bellan, M.-F., Blasco, F., 1997. La reconstitution végétale après l'agriculture itinérante à AndasibePérinet (Madagascar), Écologie, 28, 2, 149-165.

Razanaka, S., 1995. Délimitation des zones de contacts semi-arides et sub-arides de la végétation du Sud-Ouest de Madagascar. Thèse de $3^{\text {e }}$ cycle, Département de Biologie et d'Écologie végétales, Université d'Antananarivo.

Razanaka, S., 2004. La Forêt des Mikea : un espace et des ressources assiègés. Thèse d'État ès sciences, Département de Biologie et d'Écologie végétales, Université d'Antananarivo.

Terrin, S., 1998. Usages alimentaires et technologiques des végétaux spontanés dans la réoion de la forêt des Mikea (Sud-Ouest de Madagascar). Mémoire de DESS, Université Paris 12 - Valde-Marne, Créteil.

Yount, J.W., Tsiazonera, Tucker, B.T., 2001. Constructing Mikea identity: past or present links to forest and foraging, Ethnohistory, 48, 1-2, 257-291. 